\title{
Prevalence and Clinical Features of Sagging Eye Syndrome in Korean Patients
}

\author{
Beom Chan Park, Dae Hyun Kim \\ Department of Ophthalmology, Chosun University College of Medicine, Gwangju, Korea
}

\begin{abstract}
Purpose: To retrospectively analyze the relative frequency and describe the clinical features of sagging eye syndrome in Korean patients from a single center.

Methods: We retrospectively analyzed the medical records of patients with diplopia, aged over 40 years, who visited Chosun University Hospital from January 2018 to December 2020. The relative frequency of sagging eye syndrome was examined by classifying the cause of diplopia. Clinical features, such as age, sex, strabismus type, angle of deviation, treatment method, and prognosis were evaluated.
\end{abstract}

Results: A total of 128 patients were identified, of which 23 (18\%) were diagnosed with sagging eye syndrome, including 12 male patients (52.2\%) and 11 female patients (47.9\%). Their mean age was $74.6 \pm 7.6$ years (range, 61-89 years), and all patients were over 60 years. Among the 62 patients with diplopia and age over 60 years, the relative frequency of sagging eye syndrome was 23 (37.1\%), the highest among all age groups. Among the 23 patients with sagging eye syndrome, nine patients (39.1\%) had only distance esotropia, with a mean distance esotropia value of $10.1 \pm 8.6$ prism diopters (PD) (range, 4-25 PD) at the first visit; nine patients (39.1\%) had a combination of esotropia and vertical strabismus, with a mean esotropia value of $6.2 \pm 4.8$ PD (range, 2-12 PD) and a vertical angle of 4.7 3.2 PD (range, 2-10 PD); and five patients (21.7\%) had only vertical strabismus, with an average vertical strabismus angle of $3.3 \pm 1.6$ PD (range, 4-8 PD). Furthermore, 17 out of 23 patients (73.9\%) used prism glasses, in whom the symptoms of diplopia disappeared. Finally, only three patients (13.0\%) underwent surgery.

Conclusions: Sagging eye syndrome in Korean patients was identified in those over 60 years with a similar male-to-female ratio. Moreover, nonsurgical treatments, such as prism glasses, largely helped relieve the symptoms of sagging eye syndrome.

Key Words: Aging, Diplopia, Prevalence, Republic of Korea, Research

Received: August 13, 2021 Final revision: December 6, 2021 Accepted: December 13, 2021

Corresponding Author: Dae Hyun Kim, MD, PhD. Department of Ophthalmology, Chosun University Hospital, 365 Pilmun-daero, Dong-gu, Gwang-ju 61453, Korea. Tel: 82-62-220-3190, Fax: 82-62-225-9839, E-mail : eyekim@chosun.ac.kr
Aging can cause changes in various body parts, including the eyes, which can experience multiple aging-related alterations. The extraocular muscles responsible for eye movement and the orbital tissues connecting the extraocular muscles may also change due to aging. These alterations may cause strabismus or eye movement disorders in the elderly [1]. When the lateral rectus-superior rectus (LRSR) band, a connective tissue connecting the LR and SR 
muscles stretches or ruptures due to aging, the LR muscle sags downward, producing distance esotropia or vertical strabismus, in which the resulting clinical symptoms are called sagging eye syndrome [2]. According to recent international studies, the frequency of sagging eye syndrome is increasing as the average lifespan of humans is increasing with the developments in medical technology and the social environment $[3,4]$. However, the frequency and clinical features of sagging eye syndrome in the Korean population are unknown. Therefore, we aimed to analyze the relative frequency and describe the clinical features of sagging eye syndrome in adult Korean patients with diplopia.

\section{Materials and Methods}

This study was approved by the Institutional Bioresearch Ethics Review Committee of Chosun University Hospital (No. 2021-01-002). The procedures used in this study conformed to the principles of the Declaration of Helsinki. The requirement for informed consent was waived owing to the study's retrospective nature.

We retrospectively analyzed the medical records of patients with diplopia over 40 years who visited the Department of Ophthalmology at our university hospital from January 2018 to December 2020. At the first visit, the patients' age, sex, and history of systemic diseases related to strabismus, such as hyperthyroidism and myasthenia gravis, were determined. All patients underwent visual acuity examination, refraction and tonometry, anterior segment examination using a slit lamp microscope, and fundus examination using fundus imaging. The distance $(6 \mathrm{~m})$ and near $(33 \mathrm{~cm})$ angles of deviation were measured using an alternating prism cover test. Eye movement examinations and Lancaster and diplopia tests were performed to confirm the presence of diplopia and eye movement restric- tion. Eyelid changes, such as eyelid drooping and deep superior sulcus deformity, were also closely observed. Furthermore, orbital and brain magnetic resonance imaging was performed within 1 month after the initial examination to determine the presence of abnormalities in the brain parenchyma; third, fourth, and sixth cranial nerves; and orbital tissue. Additionally, changes in the extraocular muscles, especially the shape of the LR-SR band, were observed. Patients observed for at least 3 months after the initial examination were included in the study.

Based on the results of the examinations and observations listed above, the patient's diagnosis was analyzed, and the relative frequency of sagging eye syndrome was examined. The diagnostic criteria for sagging eye syndrome were as follows: patients with eyelid changes, such as blepharoptosis and deep superior sulcus deformity; those with esotropia at distance and esophoria or orthophoria at near; those with only hypotropia or with both hypotropia and esotropia; and the LR-SR band stretched or ruptured in the imaging test (Fig. 1A, 1B).

For the differential diagnosis of the fourth cranial nerve palsy, patients with excyclotorsion of hypertropic eyes, those with inferior oblique overaction or superior oblique under-action, and those with superior oblique muscle atrophy in imaging test were excluded. The patients with thyroid disease or myasthenia gravis that could cause strabismus were also excluded, although included in the diagnostic criteria for sagging eye syndrome as above. Similarly, patients with eye movement disorder of -2 or higher and those with strabismus or strabismus surgery history from childhood were also excluded.

The age and sex of the patients diagnosed with sagging eye syndrome, the strabismus type, and the distance and near angles of deviation at the first visit were analyzed. The degree of sagging of the LR muscle was measured using magnetic resonance imaging (MRI) images. In the
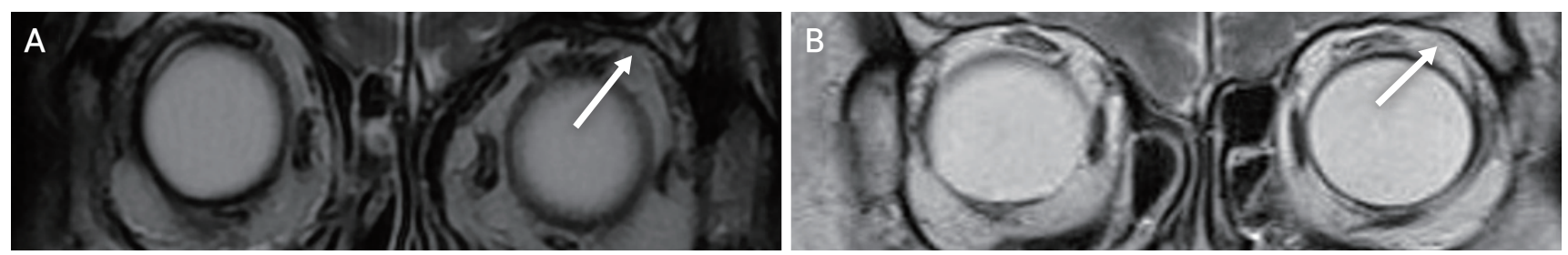

Fig. 1. Representative magnetic resonance imaging findings of a sagging eye syndrome patient. (A) Ruptured lateral rectus-superior rectus band (arrow). (B) Elongated lateral rectus-superior rectus band (arrow). The patient provided written informed consent for the publication of the research details and clinical images. 
MRI coronal view, the vertical distance between the horizontal line at the center of the eyeball and the horizontal line at the center of the LR muscle was measured. The treatment method and effect were assessed, and the surgical method and course of the patients who underwent surgical treatment were also evaluated. Moreover, the longterm prognosis was assessed by observing the change in the angle of deviation of patients who had been evaluated for more than 1 year.

Pearson chi-square test was used to compare the differences between the two groups. IBM SPSS ver. 26.0 (IBM Corp., Armonk, NY, USA) was used for all statistical anal- yses, and $p$-values $\leq 0.05$ were considered statistically significant.

\section{Results}

A total of 128 patients visited the hospital for diplopia, and there were slightly more male patients than female patients ( $p=0.161$; male patients, 68 [53.1\%]; female patients, $60[46.9 \%])$. Among the 105 patients with diseases other than sagging eye syndrome, there were slightly more male patients than female patients $(p=0.148$; male patients, 56

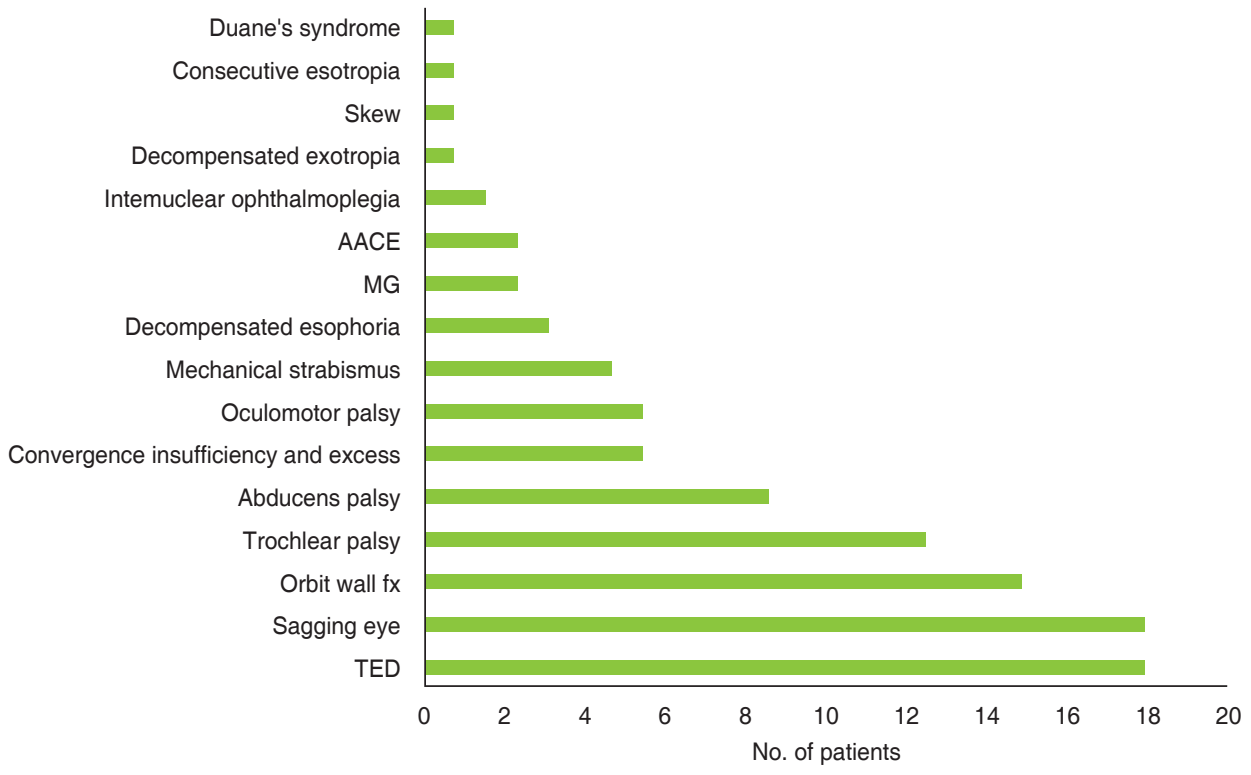

Fig. 2. Cause of diplopia in the study population (40-89 years). AACE = acute acquired comitant esotropia; $M G=m y a s t h e n i a$ gravis; fx $=$ fracture TED $=$ thyroid eye disease.

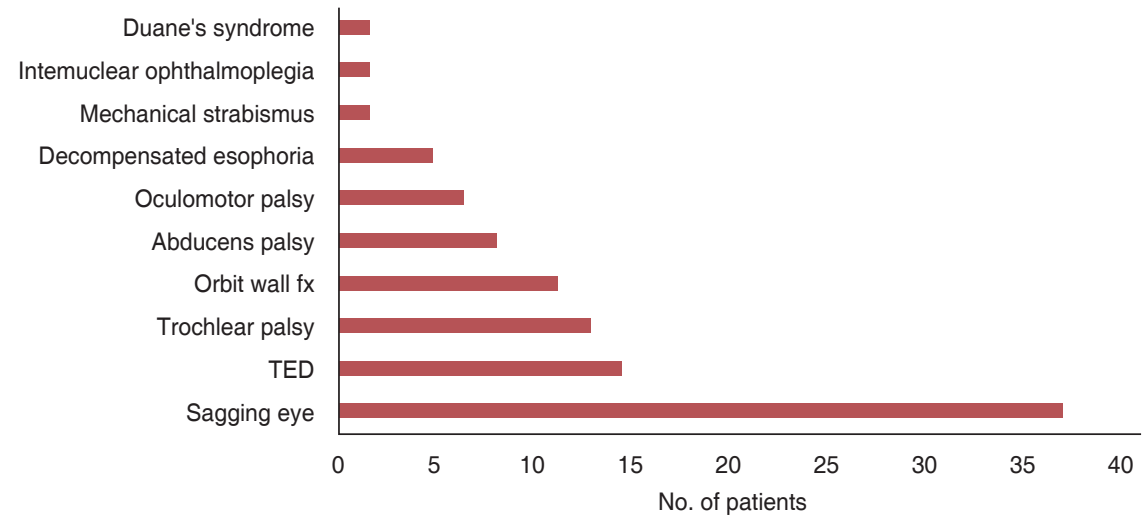

Fig. 3. Cause of diplopia in the patient subgroup older than 60 years. $f x=$ fracture; $T E D=$ thyroid eye disease. 
[53.3\%]; female patients, 49 [46.7\%]). However, among the 23 patients with sagging eye syndrome, the male-to-female ratio was similar ( $p=0.564$; male patients, 12 [52.2\%]; female patients, $11[47.8 \%])$. The average age of the 128 patients with diplopia at the first visit was $57.8 \pm 10.9$ years (range, 40-89 years), while that of 105 patients with other diseases was $56.2 \pm 12.1$ years (range, $40-89$ years). In contrast, the average age of the patients with sagging eye syndrome was $74.6 \pm 7.6$ years (range, $61-89$ years), which was higher than that of patients with diplopia and other diseases $(p<0.001)$, all of whom were over 60 years. In particular, the relative frequency of sagging eye syndrome increased with increasing age, with $20 \%$ in the 60 to 69 age group, $36.7 \%$ in the 70 to 79 age group, and $60 \%$ in the 80 to 89 age group $(p<0.05)$. When analyzing the causes of diplopia among all patients, the most common were strabismus related to thyroid ophthalmopathy in 23 patients (18.0\%) and sagging eye syndrome in 23 patients $(18.0 \%)$, followed by an orbital fracture in 19 patients (14.8\%), fourth cranial nerve palsy, and sixth cranial nerve palsy (Fig. 2). When the causes of diplopia were analyzed by classifying the patients' age into 40 to 59 years, and over 60 years, among 66 patients with diplopia aged 40 to 59 years, thyroid ophthalmopathy-related strabismus was the most common 14 (27\%), followed by orbital fracture (18.2\%), fourth cranial nerve palsy, and sixth cranial nerve palsy. None of the patients aged 40 to 59 years had sagging eye syndrome. In contrast, among the 62 patients with diplopia over 60 years, sagging eye syndrome was the most common cause of diplopia in 23 patients (37.1\%), followed by thyroid ophthalmopathy-related strabismus in eight $(12.9 \%)$, fourth cranial nerve palsy, and orbital fracture (Fig. 3). Therefore, when evaluating all patients aged over 40 years, the frequency of sagging eye syndrome was 23 of 128 patients $(18.0 \%)$, but when evaluating patients over 60 years, the frequency increased to 23 of 62 patients (37.1\%).

The mean visual acuity of patients with sagging eye syndrome at the first visit was logarithm of the minimum angle of resolution (logMAR) $0.13 \pm 7.6$ (range, $0-0.3$ ) in the right eye and $\log$ MAR $0.12 \pm 7.7$ (range, $0-0.52$ ) in the left eye. The mean spherical equivalent was sphere (sph) $+0.21 \pm 1.21$ (range, -2.87 to +2.5 ) diopters in the right eye and sph $+0.01 \pm 1.1$ (range, -3.12 to +1.75 ) diopters in the left eye. Regarding the type of strabismus, nine patients (39.1\%) had only distance esotropia; nine (39.1\%) had a combination of distance esotropia and vertical strabismus, and five $(21.7 \%)$ had only vertical strabismus. Patients with only distance esotropia had mean esotropic angles at the initial visit of $10.1 \pm 8.6$ prism diopters (PD) (range, 4-25 $\mathrm{PD}$ ) at a far distance and $4.2 \pm 5.5 \mathrm{PD}$ (range, $2-12 \mathrm{PD}$ ) at a near distance. Patients with combined vertical strabismus and distance esotropia had a mean esotropic angle of $6.2 \pm$ 4.8 PD (range, 2-12 PD) and a vertical strabismus angle of $4.7 \pm 3.2$ PD (range, 2-10 PD). Patients with only vertical strabismus had a mean vertical strabismus angle of $3.3 \pm$ 1.6 PD (range, 4-8 PD). In the imaging examination, 18 eyes of nine patients with only distance esotropia exhibited a $3.8 \pm 0.8 \mathrm{~mm}$ inferior displacement of the LR pulley; 10 eyes of five patients with only vertical strabismus exhibited a $6.8 \pm 0.9 \mathrm{~mm}$ inferior displacement of the LR pulley in the hypotropic eye; and 18 eyes of nine patients with combined vertical strabismus and distance esotropia exhibited a $7.2 \pm 1.1 \mathrm{~mm}$ inferior displacement of the LR pulley in the hypotropic eye (Table 1).

The average follow-up period of patients with sagging eye syndrome after the initial diagnosis was $18.3 \pm 25.8$ months (range, 3-108 months), of which seven patients were followed up for more than 1 year. The average observation period of these patients was $44.5 \pm 32.3$ months (range, 12-108 months); during this period, the mean distance esotropia increased from $15.3 \pm 4.8 \mathrm{PD}$ (range, $8-20 \mathrm{PD}$ ) on the first visit to $17.7 \pm 3.67 \mathrm{PD}$ (range, $12-20 \mathrm{PD}$ ) on the final visit. Moreover, the mean near esotropic angle increased from $6.7 \pm 2.7 \mathrm{PD}$ (range, $2-10 \mathrm{PD}$ ) on the first visit to $8.7 \pm 1.6 \mathrm{PD}$ (range, 6-10 PD) on the final visit, and the mean vertical strabismus angle increased from $4.7 \pm 1.2 \mathrm{PD}$ (range, 4-6 PD)

Table 1. Lateral rectus pulley inferior positions relative to globe center

\begin{tabular}{lc}
\hline Group & $\begin{array}{c}\text { Degree of lateral } \\
\text { rectus sagging }(\mathrm{mm})\end{array}$ \\
\hline Distant esotropia only & $3.8 \pm 0.8$ \\
$\quad$ 18 Eyes of nine patients & \\
Vertical strabismus only & $2.7 \pm 0.7$ \\
Five hypertropic eyes of five patients & $6.8 \pm 0.9$ \\
Five hypotropic eyes of five patients & \\
Combination type & $4.1 \pm 0.8$ \\
Nine hypertropic eyes of nine patients & $7.2 \pm 1.1$ \\
\hline
\end{tabular}

Values are presented as mean \pm standard deviation. 
Table 2. Clinical features of sagging eye patients

\begin{tabular}{|c|c|c|c|c|c|c|c|}
\hline No. & $\begin{array}{l}\text { Age } \\
(\mathrm{yr})\end{array}$ & Sex & $\begin{array}{l}\text { Initial strabismus } \\
\text { angle }\end{array}$ & MRI & $\begin{array}{c}\text { Duration of } \\
\text { follow-up (mon) }\end{array}$ & Treatment & $\begin{array}{c}\text { Final strabismus } \\
\text { angle }\end{array}$ \\
\hline 1 & 76 & Male & $\begin{array}{l}20 \Delta \mathrm{ET} \text { at D } \\
10 \Delta \mathrm{ET} \text { at } \mathrm{N}\end{array}$ & $\begin{array}{l}\text { Rt. LR-SR band elong, } \\
\text { Lt LR-SR band rupture, } \\
\text { symmetric LR sagging }\end{array}$ & 1 & Both $5 \Delta \mathrm{BO}$ prism glass & $\begin{array}{l}20 \Delta \mathrm{ET} \text { at D } \\
10 \Delta \mathrm{ET} \text { at } \mathrm{N}\end{array}$ \\
\hline 2 & 81 & Male & $6 \Delta$ LHoT at D & $\begin{array}{l}\text { Lt LR-SR band elong, } \\
\text { LLR sag vertically } \\
\text { tilting }\end{array}$ & 1 & Observation & $6 \Delta$ LHoT at D \\
\hline 3 & 89 & Male & $4 \Delta$ RHoT at D & RLR vertically tilting & 1 & Observation & $4 \Delta$ RHoT at D \\
\hline 4 & 72 & Female & $\begin{array}{l}10 \Delta \mathrm{ET}, \\
4 \Delta \mathrm{RHoT} \text { at D } \\
2 \Delta \mathrm{ET} \text { at } \mathrm{N}\end{array}$ & $\begin{array}{l}\text { Rt LR-SR band elong, Lt } \\
\text { LR-SR band rupture, } \\
\text { LLR vertical tilt }\end{array}$ & 1 & Both $5 \Delta \mathrm{BO}$ prism glass & $\begin{array}{l}10 \Delta \text { ET, } \\
4 \Delta \text { RHoT at D } \\
2 \Delta \text { ET at } N\end{array}$ \\
\hline 5 & 86 & Male & $6 \Delta \mathrm{LHoT}$ at $\mathrm{D}$ & $\begin{array}{l}\text { Both LR-SR band elong, } \\
\text { more LLR sagging }\end{array}$ & 1 & Observation & $6 \Delta \mathrm{LHoT}$ at D \\
\hline 6 & 74 & Male & $\begin{array}{l}4 \Delta \mathrm{ET} \text { at } \mathrm{D} \\
4 \Delta \mathrm{ET} \text { at } \mathrm{N}\end{array}$ & $\begin{array}{l}\text { Both LR-SR band } \\
\text { rupture, more RLR } \\
\text { vertically titling }\end{array}$ & 1 & Observation & $\begin{array}{l}4 \Delta \mathrm{ET} \text { at } \mathrm{D} \\
4 \Delta \mathrm{ET} \text { at } \mathrm{N}\end{array}$ \\
\hline 7 & 82 & Male & $\begin{array}{l}4 \Delta \text { ET at } \mathrm{D} \\
8 \Delta \mathrm{ET} \text { at } \mathrm{N}\end{array}$ & $\begin{array}{l}\text { Both LR-SR band elong, } \\
\text { LLR vertical tilt }\end{array}$ & 1 & Observation & $\begin{array}{l}4 \Delta \text { ET at } \mathrm{D} \\
8 \Delta \text { ET at } N\end{array}$ \\
\hline 8 & 80 & Female & $\begin{array}{l}6 \Delta \mathrm{ET} \text { at } \mathrm{D} \\
3 \Delta \mathrm{ET} \text { at } \mathrm{N}\end{array}$ & $\begin{array}{l}\text { Both LR-SR band elong, } \\
\text { symmetric LR sagging }\end{array}$ & 2 & Both $3 \Delta \mathrm{BO}$ prism glass & $\begin{array}{l}6 \Delta \mathrm{ET} \text { at D } \\
3 \Delta \mathrm{ET} \text { at } \mathrm{N}\end{array}$ \\
\hline 9 & 75 & Female & $10 \Delta$ ET at D & $\begin{array}{l}\text { Both LR-SR band elong, } \\
\text { symmetric LR sagging }\end{array}$ & 3 & Both $5 \Delta \mathrm{BO}$ prism glass & $10 \Delta \mathrm{ET}$ at D \\
\hline 10 & 72 & Male & $10 \Delta$ ET at D & Both LR-SR band elong & 3 & Both $5 \Delta \mathrm{BO}$ prism glass & $10 \Delta \mathrm{ET}$ at D \\
\hline 11 & 70 & Female & $\begin{array}{l}18 \Delta \text { ET, } \\
4 \Delta \text { LHoT at D } \\
8 \Delta \text { ET at } N\end{array}$ & $\begin{array}{l}\text { Both LR-SR band } \\
\text { rupture, more LLR } \\
\text { vertical tilting }\end{array}$ & 5 & Both $6 \Delta \mathrm{BO}$ prism glass & $\begin{array}{l}18 \Delta \text { ET, } \\
4 \Delta \text { LHoT at D } \\
8 \Delta \text { ET at } N\end{array}$ \\
\hline 12 & 64 & Male & $\begin{array}{l}12 \Delta \mathrm{ET} \text { at } \mathrm{D} \\
6 \Delta \mathrm{ET} \text { at } \mathrm{N}\end{array}$ & $\begin{array}{l}\text { Both LR-SR band elong, } \\
\text { symmetric LR sagging }\end{array}$ & 6 & Observation & $\begin{array}{l}12 \Delta \mathrm{ET} \text { at } \mathrm{D} \\
6 \Delta \mathrm{ET} \text { at } \mathrm{N}\end{array}$ \\
\hline 13 & 79 & Female & $\begin{array}{l}8 \Delta \mathrm{ET}, \\
10 \Delta \mathrm{LHoT} \text { at D } \\
4 \Delta \mathrm{ET} \text { at } \mathrm{N}\end{array}$ & $\begin{array}{l}\text { Rt LR-SR band elong, Lt } \\
\text { LR-SR band rupture, } \\
\text { more Lt LR sagging }\end{array}$ & 6 & Observation & $\begin{array}{l}8 \Delta \mathrm{ET}, \\
10 \Delta \mathrm{LHoT} \text { at } \mathrm{D} \\
4 \Delta \mathrm{ET} \text { at } \mathrm{N}\end{array}$ \\
\hline 14 & 78 & Male & $\begin{array}{l}12 \Delta \mathrm{ET}, \\
6 \Delta \mathrm{LHoT} \text { at D } \\
8 \Delta \mathrm{ET} \text { at } \mathrm{N}\end{array}$ & $\begin{array}{l}\text { Rt LR-SR band elong, Lt } \\
\text { LR-SR band rupture, } \\
\text { more LLR sagging }\end{array}$ & 6 & $\begin{array}{l}\text { Both } 5 \Delta \mathrm{BO} \text { Lt. } 2 \Delta \mathrm{BU}, \\
2 \Delta \mathrm{BD} \text { prism glass }\end{array}$ & $\begin{array}{l}12 \Delta \mathrm{ET}, \\
6 \Delta \mathrm{LHoT} \text { at } \mathrm{D} \\
8 \Delta \mathrm{ET} \text { at } \mathrm{N}\end{array}$ \\
\hline 15 & 86 & Male & $8 \Delta$ RHoT at D & $\begin{array}{l}\text { Rt LR-SR band rupture, } \\
\text { Lt LR-SR band elong, } \\
\text { more RLR sagging }\end{array}$ & 6 & Rt. $5 \Delta \mathrm{BD}$ prism glass & $8 \Delta$ RHoT at D \\
\hline 16 & 71 & Female & $\begin{array}{l}25 \Delta \text { ET at D } \\
12 \Delta \text { ET at N }\end{array}$ & Both LR-SR band elong & 6 & Observation & $\begin{array}{l}25 \Delta \text { ET at D } \\
12 \Delta \text { ET at N }\end{array}$ \\
\hline 17 & 77 & Female & $\begin{array}{l}14 \Delta \mathrm{ET} \text { at } \mathrm{D} \\
6 \Delta \mathrm{ET} \text { at } \mathrm{N}\end{array}$ & $\begin{array}{l}\text { Both LR-SR band } \\
\text { rupture, symmetric LR } \\
\text { sagging }\end{array}$ & 12 & Observation & $\begin{array}{l}14 \Delta \mathrm{ET} \text { at } \mathrm{D} \\
6 \Delta \mathrm{ET} \text { at } \mathrm{N}\end{array}$ \\
\hline 18 & 68 & Female & $\begin{array}{l}20 \Delta \mathrm{ET} \text { at } \mathrm{D} \\
8 \Delta \mathrm{ET} \text { at } \mathrm{N}\end{array}$ & Both LR-SR band elong & 24 & $\begin{array}{l}\text { LMR recession with } \\
\text { an adjustable suture, } \\
\text { LLR resection }\end{array}$ & Orthophoria \\
\hline 19 & 66 & Male & $\begin{array}{l}20 \Delta \text { ET at D } \\
10 \Delta \text { ET at N }\end{array}$ & $\begin{array}{l}\text { Rt LR-SR band elong, Lt } \\
\text { LR-SR band rupture, } \\
\text { LLR vertically tilting }\end{array}$ & 24 & $\begin{array}{l}\text { MR recession and } L R \\
\text { resection }\end{array}$ & Orthophoria \\
\hline 20 & 64 & Female & $4 \Delta \mathrm{LHoT}$ at $\mathrm{D}$ & $\begin{array}{l}\text { Lt LR-SR band elong, Lt } \\
\text { LR sag, oblique tilting }\end{array}$ & 36 & Lt. $4 \Delta \mathrm{BD}$ prism glass & $4 \Delta \mathrm{LHoT}$ at D \\
\hline
\end{tabular}


Table 2. (Continued)

\begin{tabular}{|c|c|c|c|c|c|c|c|}
\hline No. & $\begin{array}{l}\text { Age } \\
(\mathrm{yr})\end{array}$ & Sex & $\begin{array}{l}\text { Initial strabismus } \\
\text { angle }\end{array}$ & MRI & $\begin{array}{c}\text { Duration of } \\
\text { follow-up (mon) }\end{array}$ & Treatment & $\begin{array}{c}\text { Final strabismus } \\
\text { angle }\end{array}$ \\
\hline 21 & 61 & Female & $\begin{array}{l}18 \Delta \mathrm{ET} \text { at } \mathrm{D} \\
8 \Delta \mathrm{ET} \text { at } \mathrm{N}\end{array}$ & $\begin{array}{l}\text { Both LR-SR band elong, } \\
\text { symmetric LR sagging }\end{array}$ & 48 & $\begin{array}{l}\text { MR recession and } \\
\text { LR resection, LR } \\
\text { resection and scleral } \\
\text { fixation }\end{array}$ & $\begin{array}{l}4 \Delta \mathrm{ET} \text { at } \mathrm{D} \\
2 \Delta \mathrm{ET} \text { at } \mathrm{N}\end{array}$ \\
\hline 22 & 68 & Male & $\begin{array}{l}8 \Delta \text { ET at D } \\
2 \Delta \text { ET at } N\end{array}$ & $\begin{array}{l}\text { Both LR-SR band elong, } \\
\text { symmetric LR sagging }\end{array}$ & 60 & Both $4 \Delta \mathrm{BO}$ prism glass & $\begin{array}{l}12 \Delta \mathrm{ET} \text { at } \mathrm{D} \\
8 \Delta \mathrm{ET} \text { at } \mathrm{N}\end{array}$ \\
\hline 23 & 77 & Male & $\begin{array}{l}12 \Delta \mathrm{ET}, \\
4 \Delta \mathrm{RHoT} \text { at D } \\
6 \Delta \mathrm{ET} \text { at } \mathrm{N}\end{array}$ & $\begin{array}{l}\text { Both LR-SR band } \\
\text { rupture, more RLR } \\
\text { vertical titling }\end{array}$ & 108 & $\begin{array}{l}\text { Both } 6 \Delta \mathrm{BO}, \text { Rt. } 2 \Delta \mathrm{BU}, \\
2 \Delta \mathrm{BD} \text { prism glass }\end{array}$ & $\begin{array}{l}20 \Delta \text { ET, } \\
6 \Delta \text { RHoT at D } \\
10 \Delta \text { ET at N }\end{array}$ \\
\hline
\end{tabular}

MRI = magnetic resonance imaging; $\Delta=$ prism diopter; $\mathrm{ET}=$ esotropia; $\mathrm{D}=$ distant; $\mathrm{N}=$ near; Rt $=$ right; $\mathrm{LR}-\mathrm{SR}=$ lateral rectussuperior rectus; $\mathrm{Lt}=$ left; $\mathrm{LLR}=$ left lateral rectus muscle; $\mathrm{RLR}=$ right lateral rectus muscle; $\mathrm{BO}=$ base-out; $\mathrm{LHoT}=$ left hypotropia; $\mathrm{RHoT}=$ right hypotropia; elong = elongation; $\mathrm{BU}=$ base up; $\mathrm{LMR}=$ left medial rectus muscle; $\mathrm{MR}=$ medial rectus muscle; $\mathrm{BD}=$ base down.

on the first visit to $5.3 \pm 1.2 \mathrm{PD}$ (range, $4-6 \mathrm{PD}$ ) on the final visit. There was no change in the angle of deviation in patients observed for 1 to 3 years. In contrast, the angle of esotropia and the angle of vertical strabismus were increased in patients who had been observed for more than 4 years (Table 2).

Of the 23 patients with sagging eye syndrome, 17 (73.9\%) received prism glasses, and three $(13.0 \%)$ underwent surgical treatment. Three patients $(13.0 \%)$ were followed up without treatment. The prism glasses used a Fresnel prism or a ground-in prism. In the case of horizontal diplopia, the minimum amount of prism power at which diplopia disappeared was divided into two eyes or inserted into one eye with the base-out. In the case of vertical diplopia, it was inserted base up into the hypotropic eye. When horizontal diplopia and vertical diplopia were observed simultaneously, they were inserted horizontally on one side and vertically on the other side. The average prism powers were $4.4 \pm 1.0 \mathrm{PD}$ (range, 3-6 $\mathrm{PD}$ ) for esotropia and $3.1 \pm 1.6$ PD (range, 2-5 PD) for vertical strabismus. In all patients, diplopia disappeared after wearing prism glasses. After wearing prism glasses for the first time, some patients complained of uncomfortable symptoms such as dizziness, but they subsequently adapted to these complications. If diplopia reappeared due to increased esotropia or vertical strabismus while wearing prism glasses, the prism power was increased, and diplopia disappeared in all patients.

Three patients underwent surgery. The first patient had a distance esotropia of $20 \mathrm{PD}$ and a near esotropia of $8 \mathrm{PD}$ at the first visit. Three months after the initial visit, a medial rectus recession with an adjustable suture was performed. After 18 months, 10 PD of distance esotropia and diplopia recurred, and a LR resection was performed. After the second surgery, the diplopia disappeared, and the patient is currently being followed up. The second patient had a distance esotropia of $20 \mathrm{PD}$ and a near esotropia of $10 \mathrm{PD}$ at the first visit. The patient wore prism glasses but wanted surgical treatment later. Medial rectus recession and LR resection were performed. However, after 3 years, 25 PD of distance esotropia and diplopia recurred, and additional LR muscle resection and scleral fixation were performed. No diplopia or esotropia was observed during the 1-year follow-up after surgery. The third patient had a distance esotropia of $20 \mathrm{PD}$ and a near esotropia of $10 \mathrm{PD}$ at the first visit and used prism glasses. Two years later, medial rectus recession and LR resection were performed, and the diplopia disappeared; the patient is currently being followed up. (Table 2).

\section{Discussion}

In this study, the frequency of patients diagnosed with sagging eye syndrome among patients with diplopia over 40 years was 23 out of 128 (18\%), accounting for the highest frequency. In Goseki et al. [3]'s study, which targeted American patients, patients with diplopia aged over 40 years were reported to have the highest frequency of sagging eye syndrome (31\%), which was higher than that in our study. However, they also reported sagging eye syndrome in $4.7 \%$ of patients with diplopia aged 40 to 49 years 
and $19 \%$ of patients aged 50 to 59 years. In our study, all patients diagnosed with sagging eye syndrome were over 60 years. Therefore, since only patients with diplopia over 60 years were targeted in this study, 23 out of 66 patients (37\%) were diagnosed with sagging eye syndrome, which has a higher frequency than that in Goseki et al. [3]'s study. Furthermore, Kawai et al. [4] have examined Japanese patients aged over 60 years and found that $24 \%$ of patients diagnosed with orbital pulley disorder, which is thought to have the same definition as sagging eye syndrome, showed the highest frequency but was lower than the results of our study. It is difficult to directly compare the frequencies of sagging eye syndrome among patients with diplopia between these studies because the total number of patients and diagnostic criteria for each disease may differ between the two studies mentioned above and our study. However, all three studies have shown that the frequency of sagging eye syndrome is the highest in adult patients with diplopia. In addition, Goseki et al. [3] have reported that the frequency of sagging eye syndrome increased with age, in which $61 \%$ of patients aged over 90 years had sagging eye syndrome. In this study, $60 \%$ of patients aged over 80 years were diagnosed with sagging eye syndrome, and it is verified that the frequency of sagging eye syndrome, which is considered a senile degenerative disease, increased with age.

In this study, the male-to-female ratio of patients diagnosed with sagging eye syndrome was $52 \%$ to $48 \%$. This is different from the ratios of previous studies conducted on Caucasian patients, which reported that sagging eye syndrome was higher in women than in men, with a ratio of $60 \%$ to $85 \%[3,5,6]$. Furthermore, Goseki et al. [3] have suggested that sagging eye syndrome was more prevalent in women than men because the concentrations of estrogen and progesterone, which are female hormones that main- tain collagen and elastin constituting the orbital pulley, are decreased after menopause, causing degenerative changes in the orbital pulley and promoting the manifestations of sagging eye syndrome (Table 3) [3,4]. Currently, it is difficult to explain the reasons behind the proportion of women with sagging eye syndrome is not higher than that of men in Korean patients. Estrogen and progesterone concentrations may differ depending on race, and the extent to which these female hormones contribute to the maintenance of the orbital pulley, such as the LR-SR band, in Asian populations is unknown [7,8]. Moreover, selection bias, considering that this study comprised only patients who visited a tertiary university hospital, should also be considered. The generalizability of this result was also limited due to the small number of patients evaluated. Thus, more patients must be evaluated in future studies.

Regarding the strabismus type, the proportions of patients with distance esotropia alone and those with distance esotropia and vertical strabismus were similar (39\%), while that of those with vertical strabismus alone was relatively small (22\%). In Goseki et al. [3]'s study, the proportions of patients with both distance esotropia and vertical strabismus were similar at $35 \%$ and $37 \%$, respectively, and the proportion of patients with distance esotropia with vertical strabismus was low at $28 \%$, which differs from the results of our study. However, because the numbers of patients in this study and Goseki et al. [3]'s study are different, it is difficult to directly compare the two. In contrast, the mean distance esotropia and vertical strabismus of the patients in this study were 10 and 3.3 PD, respectively, which were similar to the results of Goseki et al. [3]'s study, which were 9.1 and 3.9 PD, respectively. As sagging eye syndrome is considered to be caused by the degeneration of the orbital tissue due to aging, it can be estimated that the angle of deviation will increase with age after the initial

Table 3. Comparison of our study with other studies on sagging eye syndrome

\begin{tabular}{lccccc}
\hline Study & $\begin{array}{c}\text { Sex ratio } \\
\text { (male : female) }\end{array}$ & $\begin{array}{c}\text { Incidence of } \\
\text { sagging } \\
\text { eye syndrome (\%) }\end{array}$ & Age (yr, mean) & \multicolumn{2}{c}{$\begin{array}{c}\text { Strabismus angle (PD) } \\
\text { esotropia }\end{array}$} \\
\hline Goseki et al. [3] [ $^{*}$ & $40.1: 59.9$ & 31.4 & 71.2 & $6.9 \pm 0.7$ & $3.0 \pm 0.3$ \\
Kawai et al. [4] & $40.0: 60.0$ & 24.1 & 72.2 & $9.1 \pm 1.4$ & $4.0 \pm 1.7$ \\
This study & $52.2: 47.9$ & 37.1 & 74.6 & $8.1 \pm 5.4$ & $3.9 \pm 1.8$ \\
\hline
\end{tabular}

$\mathrm{PD}=$ prism diopters.

*Study on American patients over 40 years of age; ${ }^{\dagger}$ Study on Japanese patients over 60 years of age. 
diagnosis. Godts and Mathysen [5] have reported that an elderly patient who had a distance esotropia of $4 \mathrm{PD}$ at the initial visit had an increase in the angle of deviation to 7 PD after 6 years and that it increased approximately twice of that in patients observed for 12 years. In patients with sagging eye syndrome who were observed for over 1 year in this study, the angle of esotropia and angle of vertical strabismus increased by 2 and 1 PD, respectively, relative to their initial visit. Furthermore, in the patient who had the longest follow-up period of 7 years after the first visit, the angle of esotropia increased from 12 to $20 \mathrm{PD}$, and the angle of vertical strabismus increased from 4 to $6 \mathrm{PD}$, which supports the above estimation.

Patients with sagging eye syndrome in this study were mainly treated with prism glasses. In $74 \%$ of such patients, diplopia disappeared with prism glasses showing satisfactory results for long-term use. Generally, diplopia treatment using prism glasses is less effective when the prism is large and in incomitant strabismus due to uncomfortable symptoms. However, prism glasses are highly effective for esotropic strabismus [9-12]. Therefore, it is hypothesized that the treatment effect of prism glasses is suitable for patients with sagging eye syndrome because the angle of deviation is relatively small, and the type of strabismus is mainly esotropia. Godts and Mathysen [5] have reported that the treatment effect was satisfactory for elderly patients with distance esotropia using a base-out prism of 2 to $16 \mathrm{PD}$ and that no surgical treatment was required. However, surgical treatment is also effective for sagging eye syndrome. In Goseki et al. [3]'s study, $50 \%$ of patients (149 of 297) with sagging eye syndrome underwent surgical treatment, and $87 \%$ of these patients were treated with a single operation and reported satisfactory results. Chaudhuri et al. [13] reported that in 87 patients with sagging eye syndrome, $72(83 \%)$ maintained orthophoria at the final follow-up after surgical treatment, and 15 (17\%) had a recurrence of diplopia. Moreover, they reported that the average postoperative observation periods for patients with and without recurrence were 635 and 229 days, respectively, indicating that patients with recurrence of diplopia had longer observation periods. It has been reported that there is a higher possibility of recurrence if the follow-up period is prolonged. In this study, two out of the three patients who underwent surgery had a recurrence of diplopia, and diplopia recurred 18 months and 3 years after the first surgery, respectively. Therefore, it is necessary to explain the possibility of recurrence when performing the surgical treatment in patients with sagging eye syndrome.

This study had the following limitations. First, the total numbers of patients with diplopia and patients with sagging eye syndrome were small. Second, this was a retrospective study. Third, only a few patients underwent surgical treatment, and finally, this study only comprised of patients who visited a single institute. Therefore, prospective studies with larger sample sizes and with patients from multiple centers are required in the future. However, this study is meaningful in that it is the first to describe the incidence and clinical features of Korean patients. In conclusion, the incidence of sagging eye syndrome in Korean adults was relatively high, and the clinical features of sagging eye syndrome were developed for patients over 60 years, with a similar male-to-female ratio and effective treatment results with prism glasses.

\section{Conflicts of Interest: None.}

Acknowledgements: None.

Funding: This study was supported by research funds from Chosun University Hospital 2021.

\section{References}

1. Clark RA, Demer JL. Effect of aging on human rectus extraocular muscle paths demonstrated by magnetic resonance imaging. Am J Ophthalmol 2002;134:872-8.

2. Chaudhuri Z, Demer JL. Sagging eye syndrome: connective tissue involution as a cause of horizontal and vertical strabismus in older patients. JAMA Ophthalmol 2013;131: 619-25.

3. Goseki T, Suh SY, Robbins L, et al. Prevalence of sagging eye syndrome in adults with binocular diplopia. Am J Ophthalmol 2020;209:55-61.

4. Kawai M, Goseki T, Ishikawa H, et al. Causes, background, and characteristics of binocular diplopia in the elderly. Jpn J Ophthalmol 2018;62:659-66.

5. Godts D, Mathysen DG. Distance esotropia in the elderly. Br J Ophthalmol 2013;97:1415-9.

6. Ridley-Lane M, Lane E, Yeager LB, Brooks SE. Adult-onset chronic divergence insufficiency esotropia: clinical features and response to surgery. $J$ AAPOS 2016;20:117-20.

7. Pinheiro SP, Holmes MD, Pollak MN, et al. Racial differences in premenopausal endogenous hormones. Cancer 
Epidemiol Biomarkers Prev 2005;14:2147-53.

8. Shimizu H, Ross RK, Bernstein L, et al. Serum oestrogen levels in postmenopausal women: comparison of American whites and Japanese in Japan. Br J Cancer 1990;62:451-3.

9. Bixenman WW. Vertical prisms: why avoid them? Surv Ophthalmol 1984;29:70-8.

10. Apers RC, Bierlaagh J. The use of prisms in paralytic squint. Am Orthopt J 1977;27:53-60.

11. Tamhankar MA, Ying GS, Volpe NJ. Effectiveness of prisms in the management of diplopia in patients due to diverse etiologies. J Pediatr Ophthalmol Strabismus 2012;49: 222-8.

12. Tamhankar MA, Luo S, Kwong B, Pistilli M. Benefits and side effects of prisms in the management of diplopia in adults: a prospective study. J AAPOS 2021;25:85.

13. Chaudhuri Z, Demer JL. Long-term surgical outcomes in the sagging eye syndrome. Strabismus 2018;26:6-10. 